\title{
Asset life cycle management: towards improving physical asset performance in the process industry
}

\author{
Charles A. Schuman \\ Alan C. Brent
}

Charles A. Schuman, Department of Engineering and Technology Management, University of Pretoria, Pretoria, South Africa

Alan C. Brent, Department of Engineering and Technology Management, University of

Pretoria, Pretoria, South Africa

Purpose - Asset management is often one of the last options to maximise cost savings in a competitive global economy due to its intrinsic complexity, especially in many developing countries. Asset management in the process industry must consider the commissioning, operational and end-of-life phases of physical assets when commencing a design and implementation project. However, current asset management models show inefficiencies in terms of addressing life cycle costs comprehensively, as well as other aspects of sustainable development. An asset life cycle management (ALCM) model is subsequently proposed for assets in the process industry, which integrates the concepts of generic project management frameworks and systems engineering with operational reliability in order to address these inefficiencies.

Design/methodology/approach - Experiences within a large petrochemical company in South Africa are used as a case study to demonstrate and discuss the different components of the proposed ALCM model.

Findings - Operational reliability and systems engineering are the means to achieve optimum value from physical assets over a facility's lifetime. Thereby, activities are identified that should be completed during each stage of the project life cycle. The application of performance measurements for the operation and support stages is proposed to influence decision making in the process industry.

Originality/value - Specific issues pertaining to the ALCM model are highlighted to ensure optimal practicality and incorporation of the model with other management practices in the process industry.

\section{Introduction}

The Boston Consulting Group has been quoted (Mitchell, 2002) to state that: "business is on the verge of a major 'next wave' of asset productivity improvement - one that will go 
farther and be more difficult to achieve than past initiatives”. The following three trends have been identified that drive this next wave (Mitchell, 2002):

1. The exhaustion of traditional cost cutting.

2. The downside of rapid growth.

3. Fundamental changes in industry structure.

Through this wave the largest challenge facing operating and production enterprises is the necessity to maintain, and often increase, operational effectiveness, revenue and customer satisfaction, while simultaneously reducing capital, operating and support costs (Mitchell, 2002, pp. 19-23). Organisations must also attain unprecedented levels of equipment availability, reliability and maintainability. The effective management of physical assets consequently plays an increasingly important role in optimising business profitability.

Asset management has been defined as: "a strategic, integrated set of comprehensive processes (financial, management, engineering, operating and maintenance) to gain greatest lifetime effectiveness, utilisation and return from physical assets (production and operating equipment and structures)" (Mitchell and Carlson, 2001). To gain even greater value, the asset management process should extend from design, procurement and installation through operation, maintenance and retirement, i.e. over the complete life cycle. In this respect, the traditional system life cycle in Figure 1 is considered (Blanchard and Fabrycky, 1998, pp. 19-29).

The figure indicates two distinct phases, namely the acquisition phase and the utilisation phase. In practice, with specific reference to the process industry, the management responsibility changes hands from one phase to the next. A research and development or a technical department will take full responsibility for the acquisition phase and will hand over to an operations department for the utilisation phase.

The challenge in managing the entire asset life cycle effectively lies in the fact that costs are isolated and addressed in a fragmented way through the various stages. During the acquisition phase, the emphasis is on implementing a technology within the boundaries of the approved budget and prescribed time frame, while ensuring that the facility conforms to the technical specifications. The primary drivers of the utilisation phase are the associated costs of product distribution, spares and inventory, maintenance, training, etc.

In this respect physical asset management in the process industry has primarily focused on maintenance management models (Amadi-Echendu, 2004; Hoskins et al., 1998, p. 123), i.e. reliability centred maintenance (RCM) (Campbell, 1995, p. 128), business centred maintenance (BCM) (Kelly, 1997) and total productive maintenance (TPM) (Campbell, 1995). Some advantages and disadvantages of these concepts are listed in Table I (Waeyenbergh and Pintelon, 2002).

A major disadvantage of applying only these models is that an estimated 65 per cent of a facility's life cycle costs (LCCs) are fixed during the design phase (Barringer, 1997). Potential cost benefits are consequently lost due to short-term cost drivers during the 
acquisition phase in the asset's life cycle. The concept of terotechnology has traditionally attempted to address this deficiency, which is a combination of management, financial, engineering and other practices applied to physical assets in pursuit of economic LCCs (Amadi-Echendu, 2004; British Standard, 1984). However, still this approach lacks the adequate consideration of the entire asset life cycle during its design phase. Furthermore, in order to enhance and sustain the value of physical assets, asset management requires a paradigm shift beyond normal cost principles of maintenance (Amadi-Echendu, 2004). For example, in addition to finance dimensions such as profit and shareholder value, customer service, innovation and learning and internal process performance such as quality, are used in new style performance measures (Bond, 1999). Also, management practices are increasingly required to demonstrate potential benefits other than costs from a sustainable development perspective (Labuschagne and Brent, 2004), e.g. the elimination of waste or the reduction in energy and water usage (Hanks, 2002).

This paper proposes a holistic asset life cycle management (ALCM) model for physical assets in the process industry by aligning and integrating the relevant elements of project management, logistics engineering, systems engineering, maintenance management and life cycle costing. In its present form the ALCM model optimises the maintenance prevention process during the acquisition phase, thereby reducing maintenance costs during the utilisation phase.

\section{Fundamentals of engineering and technology management for the ALCM model}

A comprehensive life cycle management (LCM) approach assures that the processes used across projects are consistent and that there is effective sharing and coordination of resources, information and technologies (ISO, 2002). All life cycles within a system must be considered, which spans the conception of ideas through to the retirement of the entire system. Within the process industry environment, LCM defines the processes for acquiring and supplying system products and services that are configured from the system components of hardware and humans. In addition, LCM provides for the assessment and improvement of the life cycles (ISO, 2002).

In perusing the disciplines of project management (Bonnal et al., 2002; Pillai et al., 2002; Lopes and Flavell, 1998), maintenance management (Anderson, 1998; Marquez and Heguedas, 2002), systems engineering (Blanchard and Fabrycky, 1998, pp. 19-29; Alexander et al., 2000), logistics engineering (Blanchard, 2004; Dowlatshahi, 1999) and life cycle costing (Woodward, 1997; Blanchard and Fabrycky, 1998, pp. 557-602;

Hunkeler and Rebitzer, 2003) in the LCM context, certain fundamentals are recognized from a cost perspective:

- The development cycle of a system, production plant or facility is initiated with the identification of a need (Figure 1).

- The system, production plant or facility requires maintenance and support during its operational lifetime in order to continue to fulfil the identified need. 
- A life cycle approach is, therefore, required to reduce operating and maintenance costs and optimise the productivity of the plant and maintenance and support design should be engineered concurrently to the design of the system.

- The requirements with regard to system effectiveness in terms of reliability, availability and maintainability are of equal importance to the functional requirements of throughput, quality, capital cost, schedule, etc. It is critical that the first-mentioned requirements should also be defined during the conceptual phase.

These fundamental concepts must be viewed as part of an effective asset management strategy, which has become a focus area of many companies to acquire and sustain a competitive advantage within a global economy.

\section{The interfaces between project execution and ALCM in terms of operational reliability}

\section{Framework for project management}

A basic project management framework, which is practitioner-oriented (Buttrick, 2000) and follows the described straightforward approach to technical project life cycles (Bonnal et al., 2002), serves as the foundation of the proposed ALCM model. The framework divides a project into different "stages", which are separated by "gates". Stages refer to specific time periods during which groups of activities are performed and deliverables created that are evaluated at the subsequent gates. Gates are the decision points that precede every stage and the subsequent stage should not commence unless specific criteria have been met. Figure 2 (Buttrick, 2000) shows the Buttrick framework, adapted to be better suited to the design, construction and commissioning of a chemical processing plant.

\section{Operational reliability}

Operational reliability is defined as a flexible process that optimises people, processes and technology, and thereby enabling companies to become more profitable by maximising availability and value addition of producing assets (Duran, 2000). Operational reliability is based on four key elements that should be addressed jointly to ensure long-term continuous improvement towards optimisation. The four elements or focus areas of operational reliability are human reliability, equipment reliability, equipment maintainability and process reliability. The four elements are summarised in Figure 3 (Duran, 2000). The full integration of the operational reliability elements ensures a comprehensive maintenance approach, which will extend the life span of assets. For example, the four elements are integral to the maintenance prevention (MP), preventative maintenance (PM) and corrective maintenance (CM) components of a comprehensive maintenance and reliability strategy, each of which, in turn, are important in the different life cycle phases of an asset in the process industry. This is illustrated in Figure 4 (Akiho, 2002). 


\section{ACLM performance measurements}

Performance measurements that will be used during the operation and support phase of an asset's life cycle will determine decisions during early stages of the asset project. It is, therefore, very important to identify the measures to be used and the applicable targets and benchmarks as accurately as possible.

Usually, assumptions are made to determine the maintenance cost at an early stage and maintenance cost benchmarks can be used, such as maintenance cost as a percentage of equipment replacement value (Mitchell, 2002, p. 40). In this case the maintenance department, that will eventually be responsible for maintenance, must make their measures and benchmarks clear to the project team. As an example, in the process industry, a typical target for maintenance cost of between 1.5 and 2 per cent of equipment replacement value can be stated.

As the project progresses and more information on asset details become available during the detailed design stage, the expected maintenance cost should be re-calculated more accurately based on reliability strategies. The latest cost indications should be compared to the initial budget estimate and if significant deviations are found, cost effective alternatives should be considered. Studies on LCCs should be conducted and the best option selected (Fabrycky and Blanchard, 1991).

In this manner, maintenance measurements that will actually be used during the operation and support phase of an asset's life cycle will guide the decisions that are made during the early stages of project execution.

\section{Proposed ALCM model}

The proposed ALCM model for the process industry integrates the different frameworks that have been discussed above, and is illustrated in Figure 5. Thereby, the model consists of three levels the project management framework, the asset life cycle and operational reliability. The model is further described based on the different components of the asset life cycle level.

\section{Identify needs for assets}

The identification of a need for assets will begin during the initial investigation stage of a project in the process industry. The focus during this project stage is on investigating and evaluating the process requirements and there is very little detail on the actual assets. The required assets are specified in broad terms. It is only known at this stage if a facility, e.g. a refinery, capable of producing a specific volume of a certain product, e.g. fuel, is required. 


\section{Conceptual and preliminary design}

Conceptual and preliminary design of the system takes place during the detailed investigation stage of the project.

An early investment in human reliability instils a sense of ownership in the project by involving a team of multi-skilled people from the operating, production and maintenance disciplines upfront. At this early stage, concerns are addressed and practical obstacles removed as production and maintenance viewpoints are allowed to influence decisions. Initial assumptions are made regarding future human capacity and the skills required for operating and maintaining the facility. For example, where a new technology is purchased, specific training programmes must be considered as part of the purchasing agreement.

The process flow diagrams (PFDs) developed during this stage are an important facet of process reliability as it illustrates the basic flow of the process. These diagrams are key deliverables of the stage and show the main equipment and include design parameters (pressure, temperature, flow), mass balances and controls. The design envelope is specified during this stage.

Equipment maintainability is addressed by studying the preliminary equipment layouts. The complexity of the processing plant is roughly formulated and from the preliminary number of equipment and estimated size of facility, initial assumptions are made on maintainability. The maintenance approach is developed during this stage and includes assumptions on the levels of maintenance support required and basic responsibilities for support.

In terms of equipment reliability, the first question that should be answered is the anticipated design life of the facility. This is critical, as it will be the input to all reliability issues and LCC analyses. Material selection is done with contributions from design engineers, metallurgical engineers and maintenance and reliability engineers.

A high level system breakdown structure (SBS) is derived from the PFDs to visualise the functional position of a piece of equipment according to the process in which it operates. The first round criticality ranking is drafted, based on the process functions of major systems or equipment. The criticality ranking process enables a better understanding and assists to identify systems or equipment that are critical for normal operations. Considering the process requirements and based on the criticality ranking, it is possible to make decisions regarding redundancy. With the expected output known, as well as the impact certain equipment may have on the process, it can, therefore, be decided what systems must be furnished with standby systems. 


\section{Detail design and development}

This stage of the system development process synchronises with the development stage of the project management framework.

The contribution by operation and maintenance personnel increases greatly as more and more details become available on the process and equipment and this information is disseminated to them. The assumptions on manpower requirements can be refined into an operations organisational structure (OOS). Depending on the duration of this and following stages, recruitment of suitable personnel can commence.

The PFDs are further developed into mechanical flow diagrams (MFDs) that graphically illustrate all equipment and interconnecting piping, materials, design and operating data, location of instruments and pressure relieving devices. The operating parameters within which the process should be controlled are defined during this stage. This forms the basis for future managing operations within agreed parameters that is the foundation for process reliability.

MFDs and process data sheets will provide sufficient information on sizes, materials and layout to provide the scope for the first round requirements for equipment maintainability. Although there is not yet a three-dimensional representation of the plant, certain requirements on maintainability, for example minimum distances between equipments, can be specified to vendors and contractors.

All levels of the SBS are completed and the criticality ranking revisited to include all equipment not yet covered in the previous stage. Equipment identified as critical are subjected to a failure mode effect analysis (FMEA) to identify possible failure modes. Development of equipment maintenance strategies is the extension of the FMEA process. RCM logic (Campbell, 1995, p. 128) is followed, whereby preventive and predictive maintenance tasks are identified that will detect, mitigate or prevent the anticipated failure modes from occurring. Where there are no preventive or predictive tasks possible, or when these tasks are not cost-effective, a run to failure strategy is adopted, i.e. a totally reactive approach whereby equipment is only repaired after failure has occurred. During the equipment strategy development process, it is advised to follow an approach whereby the equipment criticality determines the effort required to reach a suitable strategy.

If it is found that it may not be cost-effective to operate specific equipment within the expected reliability parameters, alternative solutions should be considered. Trade-offs between initial capital expenditure and operation and maintenance costs should be analysed and the best solution selected.

With the criticality ranking and reliability strategy defined, improved decisions can be made on requirements for online condition monitoring systems. Cost-risk studies are done where installation costs are compared to maintenance expenditure and potential production losses due to equipment failures. 
The reliability strategy results in schedules and task lists that can be entered into the computerised maintenance management system (CMMS). Although it is not always possible to populate the CMMS at this stage, the intention should be to do it as early as possible, as it is the easiest way to quantify the reliability strategy. Modern CMMS systems have the capability to derive costs from the equipment strategy and high cost strategies can then be highlighted, and necessary alternative equipment or strategies considered.

\section{Construction and/or production}

The construction and/or production of the system or process facility takes place during the execution stage of the project management framework. As the physical plant nears completion, the operating and maintenance personnel become fully involved.

To facilitate human reliability, operating and maintenance personnel are trained during this stage. It is important, especially for operating personnel, to complete training before the critical start-up. The pre-commissioning and commissioning periods, preceding operations when the actual product is manufactured, also provide valuable training opportunities that should be fully exploited.

As the physical plant is being completed, the actual accessibility can be evaluated. Although it is a late stage in the project for major changes, recommendations should still be considered in terms of LCC and the most favourable solution implemented. Parallel with equipment procurement and construction, spare part requirements are evaluated. It is good practice to conduct cost-risk studies to assist in deciding on whether and how many expensive, slow moving spares should be kept. Ideally, all spare parts must be on site prior to start-up to prevent any unnecessary downtime. Standardisation and interchangeability are considered to reduce the amount of stock held and the number of maintenance procedures.

Specialised tasks, required for the future maintenance of the equipment, are identified and special tools procured or constructed during this phase to ensure that all equipment can be properly maintained after start-up. It should not be assumed that maintenance artisans would be able to maintain a wide array of equipment. The impact of new technology on maintenance capability is often underestimated and it is important to thoroughly evaluate all expected maintenance tasks for complexity and familiarity. Gaps should be identified and thorough, detailed maintenance procedures compiled. As part of the human reliability component, the necessary maintenance training should also be completed during this stage.

In the process industry, the tenders are usually evaluated during this stage (Steer, 2003), considering technical conformance to specifications and capital layout. Bids are no longer evaluated solely on capital layout, but the tendency is for LCC and total cost of ownership to carry a significant weightage. It would obviously be ideal if vendors, with thorough knowledge of the acquired parts, could submit a tender and provide the estimated LCCs for the equipment. 
Another emerging trend is to enter into a service contract with a supplier whereby the supplier is held responsible to maintain the equipment (Auramo et al., 2003). With such an agreement it is in the best interest of the supplier to supply equipment with the lowest LCC. The client will benefit, as more reliable equipment will be supplied, resulting in fewer breakdowns and potentially less production losses. Maintenance contracts suited to both parties are most desirable, but proper guarantees and warranties should be agreed upon and thoroughly documented.

Towards the later stages of the construction phase, the operating and maintenance personnel become involved with plant checkouts. It is very important for process reliability, as well as equipment maintainability that skilful and experienced people are used to perform these functions. During the checkouts, conformance to process and maintainability requirements are confirmed and approved. End-of-job documentation that includes operating manuals, maintenance manuals, code data books and as-built drawings should be available at commissioning.

At the end of the stage all equipment should have a suitable reliability strategy and the CMMS must be fully populated to implement the strategies directly after start-up.

\section{System utilisation and life cycle support}

Operating the plant within the design parameters supports process reliability during system utilisation. During the previous stages these parameters were defined and used to develop reliability strategies. It is now required to operate the plant within these parameters. From a production point of view it is important to operate the plant at most effective and efficient throughput. From a maintenance perspective, operating the equipment outside the design parameters may have adverse effects on the equipment condition. A management system to monitor the operations and flag deviations is essential.

Work management plays an important role in reducing mean time to repair (MTTR), the prime measurement for equipment maintainability (Figure 3). Effective management processes and systems should be followed to ensure that work is identified in time and that the description is clear enough for the maintenance planner and supervisor to know what must be done. A suitable and well-defined priority system ensures that high priority tasks are awarded the necessary attention within the agreed time frame. It also allows for improved planning and scheduling of less urgent or important tasks. This reduces time wastage and ensures that resources, both services and material, are available when the job commences.

The reliability strategies that were developed and entered into the CMMS during the previous stages are implemented during the system utilisation and support phase. These plans are executed via the work management process as discussed in the previous paragraph. An important aspect during this stage is the collection of failure data. The operators gather the data on the plant and feed it into the CMMS in order to build the foundation for reliability analysis. This data is used to evaluate whether the reliability 
strategies are effective or needs to be revised. It is also the source data for conducting root cause failure analysis with the aim to eliminate defects.

During this stage, both online condition monitoring and scheduled condition-based maintenance tasks must be diligently executed, monitored and corrective actions taken when deviations occur.

\section{Retirement}

Although a chemical plant is designed with a finite lifetime, the plant normally significantly exceeds the anticipated life. Some systems of the plant may become worn and need to be replaced, but it is rare that the whole plant is retired. During all stages of the system development, possible retirement should be kept in mind, and the system should be designed such that, if required, it can be disposed of at minimum cost in the most environmentally responsible manner. If the retired system needs replacement, the complete project management framework and corresponding system development steps are followed again.

\section{Conclusions}

Within an increasingly competitive global economy that enforces the maximising of cost savings with subsequent profit increases, successful companies have demonstrated an understanding and commitment to two key issues that have been identified (Latino, 2000): increased productivity and growth. It is proposed that both of these objectives can be achieved if new projects are identified and executed while simultaneously focusing on optimising the value from assets over the life cycle of a facility in the process industry.

The ALCM model proposed in this paper, guides decisions made during the early stages of a project in the process industry in order to increase the long-term performance of assets at reduced LCCs. By using the concepts typical to operational reliability during project execution, the model includes the main areas of asset management (Coetzee, 1999): a topdown approach addressing policy, a maintenance plan and procedures, maintenance information, operational systems and maintenance operations.

The implementation of the proposed strategy requires an understanding and acknowledgement from corporate management that asset management commences at the initial investigation stage of a project. The incorporation of specific asset management components requires the modification of the well-established formal project management frameworks. In this respect it is recommended that a multi-skilled task team should consider asset management during the design and construction phases of a facility and not only during the operation and support phases as is often the case in the process industry. This will enable cost saving and profit increase and may prove to be the deciding factor 
providing the competitive edge to the final product. However, the theoretically proposed ALCM model cuts across all strategic, operational and tactical levels and a distinction between these levels must be recognised from an overall management perspective.

The ALCM model must be further tested within the process industry to determine if the holistic approach does overcome the disadvantages that cause the maintenance models not to address PM adequately in the acquisition phase of assets. Also, in its present form, the ALCM model focuses on the total maintenance costs only. Additional aspects of corporate sustainability must be considered in terms of asset performance (Labuschagne et al., 2004) and the model must be revised accordingly.

Figure 1 Life cycle phases of process asset systems

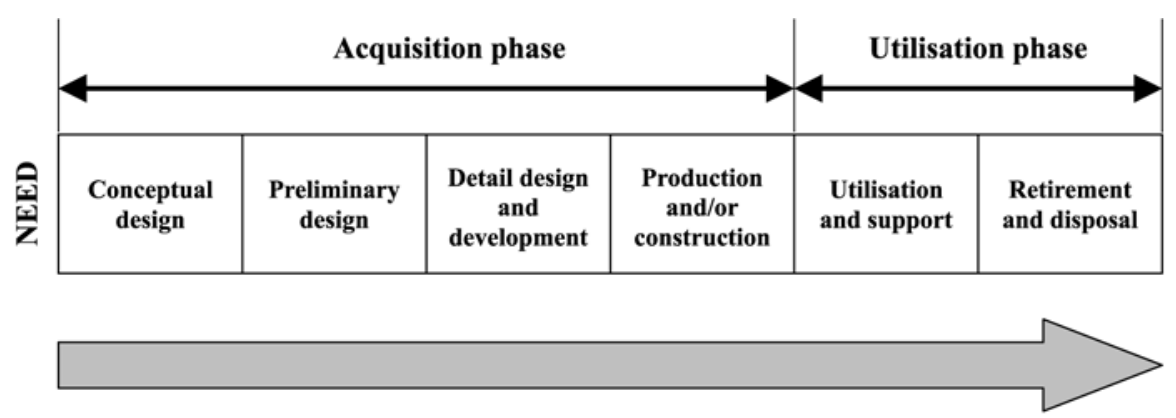

Source: Blanchard and Fabrycky (1998)

Figure 2 Project management framework as basis for the ALCM model

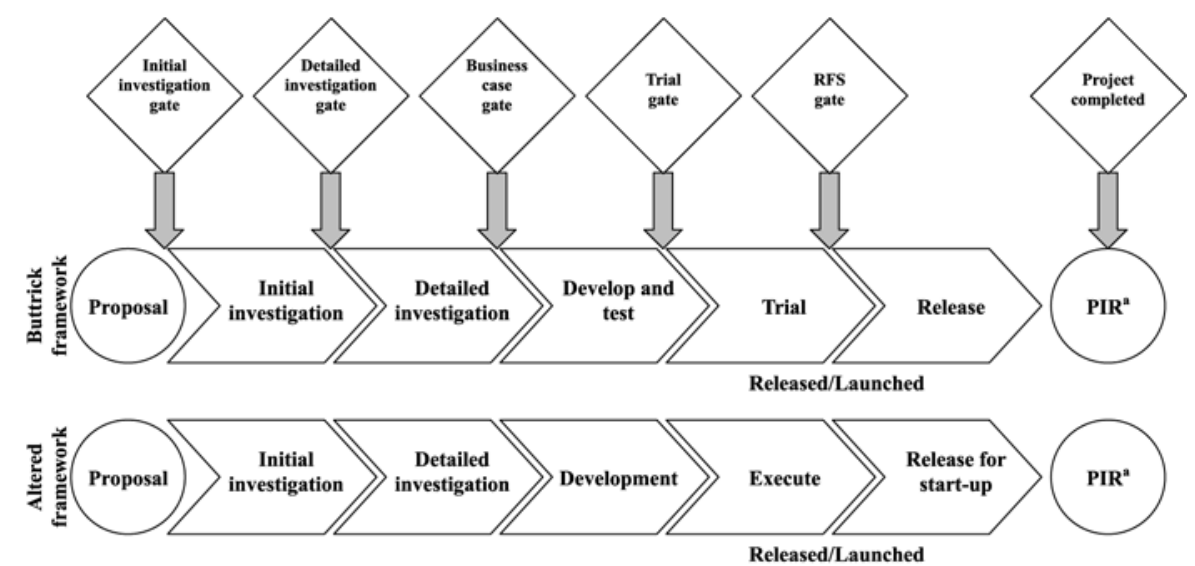

Note: aPIR refers to the Post Implementation Review 
Figure 3 The four essential elements of operational reliability

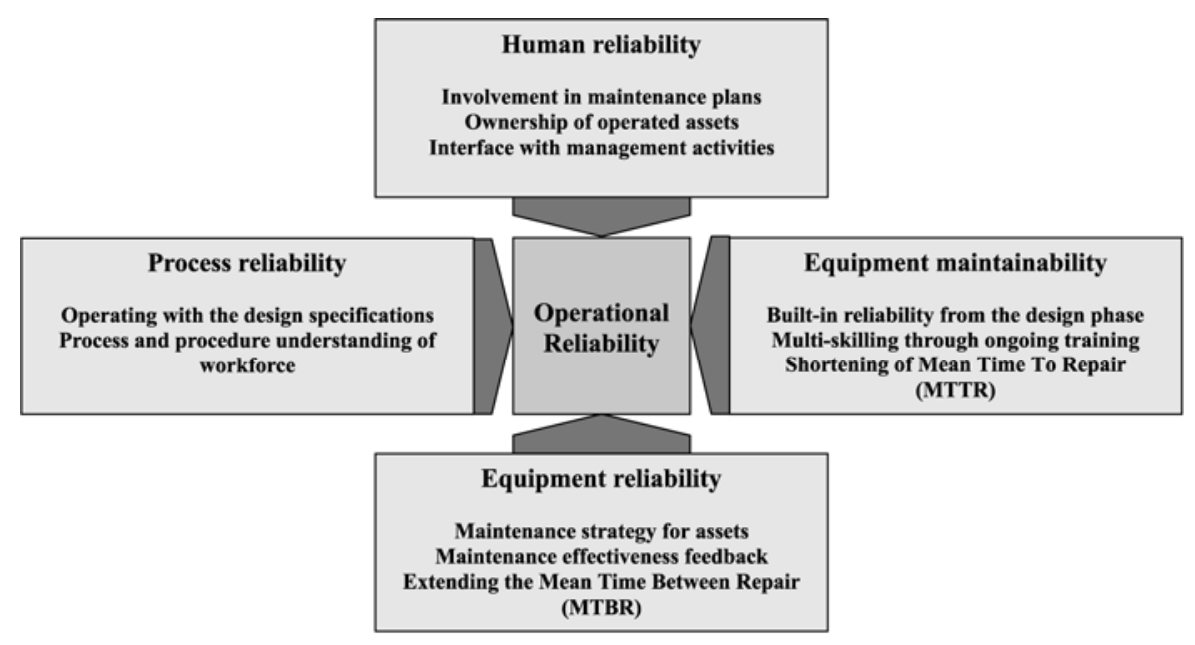

Source: Duran (2000)

Figure 4 Maintenance framework to extend the life span of assets

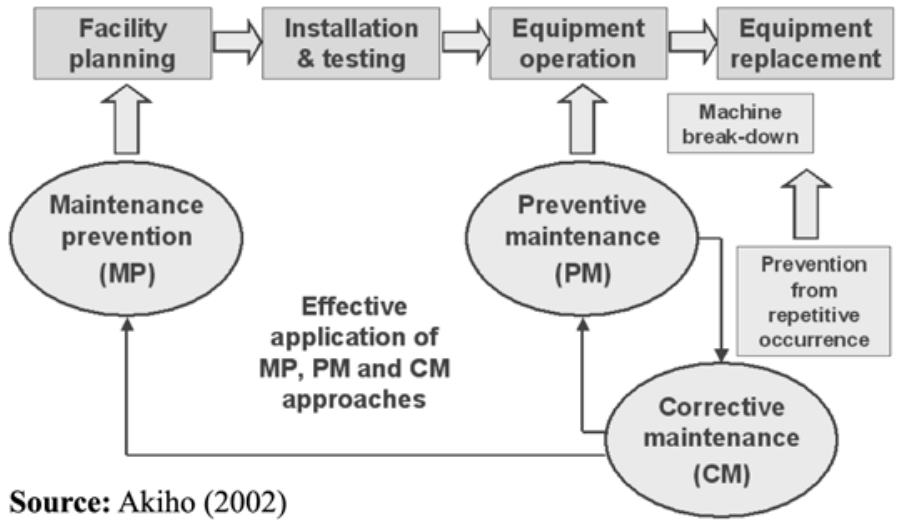


Figure 5 The proposed asset life cycle management (ALCM) model (a) PIR refers to the post implementation review

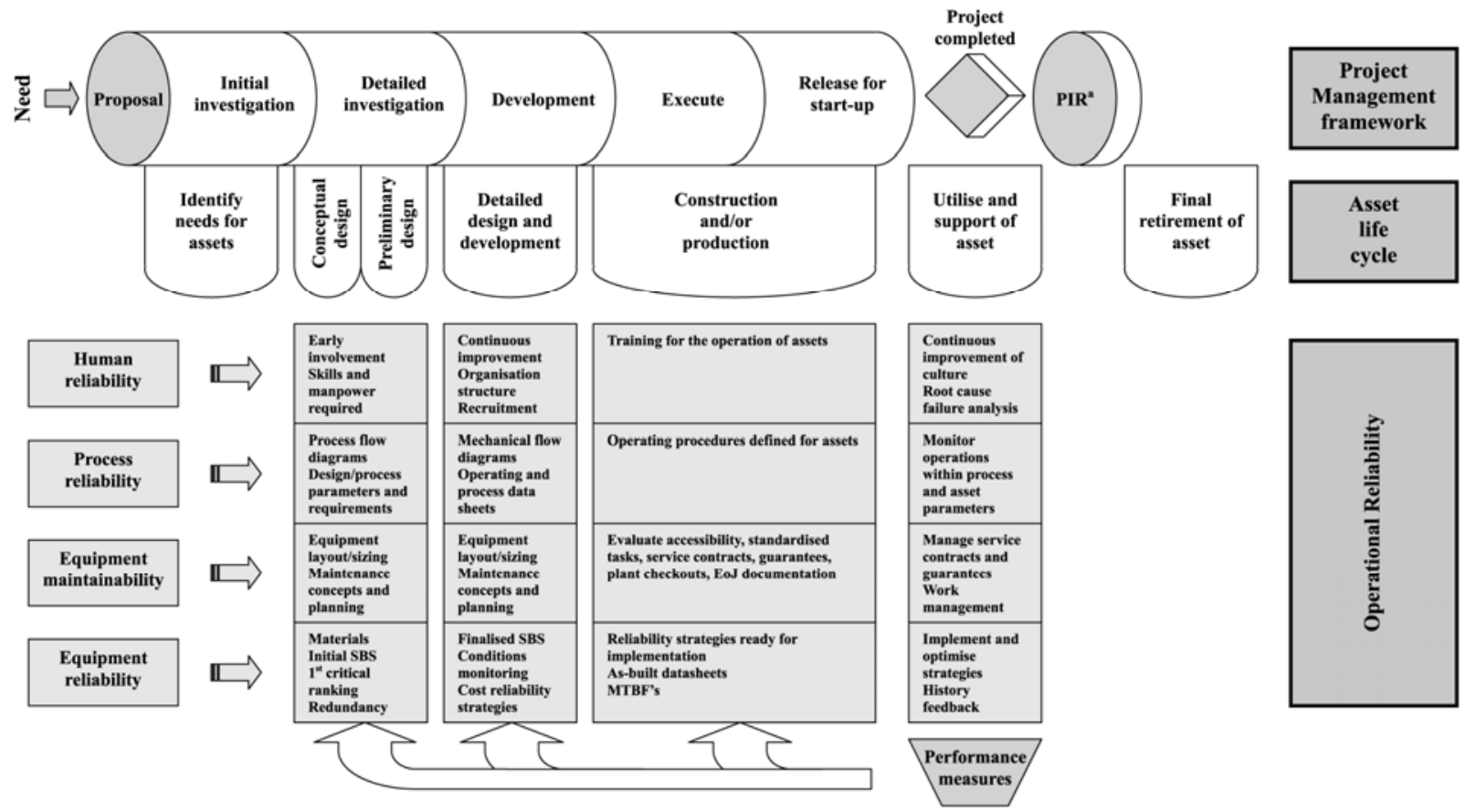

Note: aPIR refers to the Post Implementation Review

Table I An overview of maintenance concepts or models

\begin{tabular}{|c|c|c|c|}
\hline $\mathrm{RCM}$ & $\mathrm{BCM}$ & TPM & LCC \\
\hline $\begin{array}{l}\text { Advantages } \\
\text { Traceability }\end{array}$ & Accuracy & $\begin{array}{l}\text { Increased productivity } \\
\text { (improvement of } \\
\text { operations/workplace) }\end{array}$ & $\begin{array}{l}\text { Improvement of the designer-user interface } \\
\text { (engineering approach) }\end{array}$ \\
\hline Cost savings & $\begin{array}{l}\text { Business-centred } \\
\text { approach }\end{array}$ & $\begin{array}{l}\text { Increased quality } \\
\text { (TQM-link) }\end{array}$ & Life cycle cost is of central importance \\
\hline Rationalisation & $\begin{array}{l}\text { Integrated } \\
\text { auditing } \\
\text { possibilities }\end{array}$ & Cost reduction & $\begin{array}{l}\text { Correct adaptation brings considerable } \\
\text { benefits in most cases }\end{array}$ \\
\hline Plant improvement & & $\begin{array}{l}\text { Increased moral, safety } \\
\text { and environmental care }\end{array}$ & Feedback of information on design \\
\hline $\begin{array}{l}\text { Education } \\
\text { Involves operators and maintainers }\end{array}$ & & Involves the operators & Full integration \\
\hline $\begin{array}{l}\text { Disadvantages } \\
\text { Complexity }\end{array}$ & Complexity & $\begin{array}{l}\text { Not really a maintenance } \\
\text { concept }\end{array}$ & Rather theoretical management philosophies \\
\hline $\begin{array}{l}\text { Extensive need of data } \\
\text { Focus on "reliability" }\end{array}$ & $\begin{array}{l}\text { Extensive need } \\
\text { of data }\end{array}$ & $\begin{array}{l}\text { No decision rules for } \\
\text { basic maintenance } \\
\text { policies } \\
\text { Cost and profit are not } \\
\text { taken into account }\end{array}$ & $\begin{array}{l}\text { Difficult implementation, life cycle cost } \\
\text { analysis is complex (cash constraints, time } \\
\text { constraints, uncertainty of forecasting, etc.) }\end{array}$ \\
\hline $\begin{array}{l}\text { Does not fully recognise that proper maintenance is also } \\
\text { an economic problem, no concept improvement } \\
\text { mechanism available (no feedback) }\end{array}$ & & & $\begin{array}{l}\text { Less structured (collection of procedures } \\
\text { rather than unambiguous standard method) }\end{array}$ \\
\hline Source: Waeyenbergh and Pintelon (2002) & & & \\
\hline
\end{tabular}




\section{References}

Akiho, L. (2002), Overview of Total Productive Maintenance, case studies of best practice of the Japanese manufacturing industry, ChuSanRen (Central Japan Industries Association), Nagoya.

Alexander, B., Barton, G., Petrie, J., Romagnoli, J. (2000), "Process synthesis and optimisation tools for environmental design: methodology and structure", Computers and Chemical Engineering, Vol. 24 pp.1195-200.

Amadi-Echendu, J.E. (2004), "The paradigm shift from maintenance to physical asset management", IEEE Transactions on Engineering Management.

Anderson, D. (1998), "Mtce jungle: the maintenance theory jungle", Maintenance \& Asset Management, Vol. 13 No.5, pp.3-8.

Auramo, J., Tanskanen, K., Småros, J. (2003), "Increasing operational efficiency through improved customer service - a case from the process maintenance business", paper presented at Logistics Research Network (LRN), 8th Annual Conference, London.

Barringer, H.P. (1997), "Life cycle cost and reliability for process equipment", paper presented at 8th Annual Energy Week Conference and Exhibition, Houston, Texas.

Blanchard, B.S. (2004), Logistics Engineering and Management, 6th ed., Prentice-Hall, Upper Saddle River, NJ, pp.15-21.

Blanchard, B.S., Fabrycky, W.J. (1998), Systems Engineering and Analysis, 3rd ed., Prentice-Hall, Upper Saddle River, NJ.

Bond, T.C. (1999), "The role of performance measures in continuous improvement", International Journal of Operations \& Production Management, Vol. 19 No.12, pp.1318-44.

Bonnal, P., Gourc, D., Lacoste, G. (2002), "The life cycle of technical projects", Project Management Journal, Vol. 33 No.1, pp.12-19.

British Standard (1984), Maintenance Management Terms in Terotechnology, BS:3811, BSI, London.

Buttrick, R. (2000), The Interactive Project Workout: Reap Rewards from All Your Business Projects, 2nd ed., Financial Times, Prentice-Hall, London, pp.58-9.

Campbell, J.D. (1995), Uptime: Strategies for Excellence in Maintenance Management, Productivity Press, New York, NY. 
Coetzee, J.L. (1999), "A holistic approach to the maintenance problem", Journal of Quality in Maintenance Engineering, Vol. 5 No.3, pp.276-80.

Dowlatshahi, S. (1999), "A modeling approach to logistics in concurrent engineering", European Journal of Operational Research, Vol. 115 No.1, pp.59-76.

Duran, J. (2000), What Is Operational Reliability?, available at: www.tpmonline.com/articles_on_total_productive_maintenance/reliability/operationalrelia bility.htm(accessed 5 August 2004).

Fabrycky, W.J., Blanchard, B.S. (1991), Life-cycle Cost and Economic Analysis, PrenticeHall, Upper Saddle River, NJ, pp.122-41.

Hanks, J. (2002), Promotion of Environmental Management in the Private Sector of the Republic of South Africa, prepared by Common Ground Consulting, Deutsche Gesellschaft für Technische Zusammenarbeit (GTZ) GmbH, Eschborn.

Hoskins, R.P., Brint, A.T., Strbac, G. (1998), "A structured approach to asset management within the electricity industry", Utilities Policy, Vol. 7 pp.221-32.

Hunkeler, D., Rebitzer, G. (2003), "Life cycle costing - paving the road to sustainable development?", International Journal of Life Cycle Assessment, Vol. 8 No.2, pp.109-10.

International Organisation for Standardisation (ISO) (2002), Systems Engineering-System Life Cycle Processes, ISO/IEC 15288:2002 standard, available at: www.iso.org, .

Kelly, A. (1997), Maintenance: Organization and Systems, Reed Educational and Professional Publishing Ltd, Oxford, pp.1.

Labuschagne, C., Brent, A.C. (2004), "Sustainable project life cycle management: the need to integrate life cycles in the manufacturing sector", International Journal of Project Management.

Labuschagne, C., Brent, A.C., van Erck, R.P.G. (2004), "Assessing the sustainability performances of industries", Journal of Cleaner Production, Vol. 13 No.4, pp.373-85.

Latino, C.J. (2000), The Pioneering of Reliability into the 21st Century, keynote speech, Petroelos de Venezuela 3rd National Maintenance Workshop, Caracas.

Lopes, M.D.S., Flavell, R. (1998), "Project appraisal - a framework to assess nonfinancial aspects of projects during the project life cycle", International Journal of Project Management, Vol. 16 No.4, pp.223-33.

Marquez, A.C., Heguedas, A.S. (2002), "Models for maintenance optimization: a study for repairable systems and finite time periods", Reliability Engineering \& System Safety, Vol. 75 pp.367-77. 
Mitchell, J.S. (2002), Physical Asset Management Handbook, 3rd ed., Clarion Technical Publishers, Houston, TX.

Mitchell, J.S., Carlson, J. (2001), "Equipment asset management - what are the real requirements?", Reliability Magazine, October, pp.4-14.

Pillai, A.S., Joshi, A., Srinivasa Rao, K. (2002), "Performance measurement of R\&D projects in a multi-project, concurrent engineering environment", International Journal of Project Management, Vol. 20 pp.165-77.

Steer, F. (2003), "Using your supply chain as an integral part of achieving optimal maintenance efficiency", paper presented at special closing address, Process Industry Maintenance Conference, Brussels.

Waeyenbergh, G., Pintelon, L. (2002), "A framework for maintenance concept development", International Journal of Production Economics, Vol. 77 No.3, pp.299313.

Woodward, D.G. (1997), "Life cycle costing - theory, information acquisition and application", International Journal of Project Management, Vol. 15 No.6, pp.335-44.

Oliverson, R.J. (1997), "Preventable maintenance costs more than suspected", Maintenance Technology, Vol. 10 No.8, pp.23-5. 